\title{
Runaway Modeling in ORMAK and TNS
}
A. Cooper
D. W. Swain
F. B. Marcus
T. Kammash

\section{OAK RIDGE NATIONAL LABORATORY}

OPERATED BY UNION CARBIDE CORPORATION FOR THE ENERGY RESEARCH AND DEVELOPMENT ADMINISTRATION 


\section{DISCLAIMER}

This report was prepared as an account of work sponsored by an agency of the United States Government. Neither the United States Government nor any agency Thereof, nor any of their employees, makes any warranty, express or implied, or assumes any legal liability or responsibility for the accuracy, completeness, or usefulness of any information, apparatus, product, or process disclosed, or represents that its use would not infringe privately owned rights. Reference herein to any specific commercial product, process, or service by trade name, trademark, manufacturer, or otherwise does not necessarily constitute or imply its endorsement, recommendation, or favoring by the United States Government or any agency thereof. The views and opinions of authors expressed herein do not necessarily state or reflect those of the United States Government or any agency thereof. 


\section{DISCLAIMER}

Portions of this document may be illegible in electronic image products. Images are produced from the best available original document. 


\section{Printed in the United States of America. Available from National Technical Information Service \\ U.S. Department of Commerce 5285 Port Royal Road, Springfleld, Virginia 22161 \\ Price: Printed Copy $\$ 4.00$; Microfiche $\$ 3.00$}

This report was prepared as an account of work sponsored by the United States Government. Neither the United States nor the Energy Research and Development Administration/United States Nuclear Regulatory Commission, nor any of their employees, nor any of their contractors, subcontractors, or their employees, makes any warranty, express or implied, or assumes any legal liability or responsibility for the accuracy, completeness or usefulness of any information, apparatus, product or process disclosed, or represents that its use would not infringe privately owned rights. 
Contract No. W-7405-eng-26

FUSION ENERGY DIVISION

RUNAWAY MODELING IN ORMAK AND TNS

A. Cooper

University of Michigan, Ann Arbor, Michigan

D. W. Swain

F. B. Marcus

T. Kammash

University of Michigan, Ann Arbor, Michigan

Date Published - July 1977

NOTICE This document contains information of a preliminary nature. It is subject to revision or correction and therefore does not represent a final report.

Prepared by the

OAK RIDGE NATIONAL LABORATORY

Oak Ridge, Tennessee

operated by

UNION CARBIDE CORPORATION

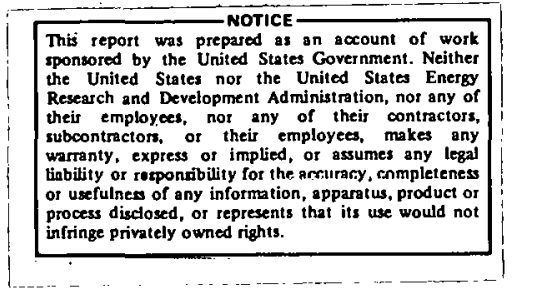

for the

ENERGY RESEARCH AND DEVELOPMENT ADMINISTRATION 


\section{THIS PAGE}

\section{WAS INTENTIONALLY LEFT BLANK}




\section{CONTENTS}

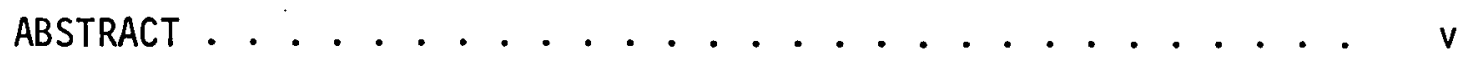

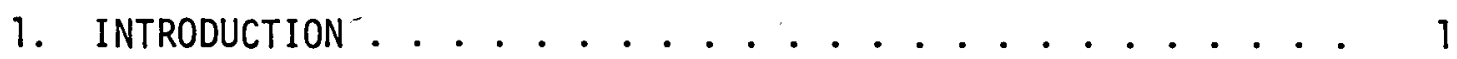

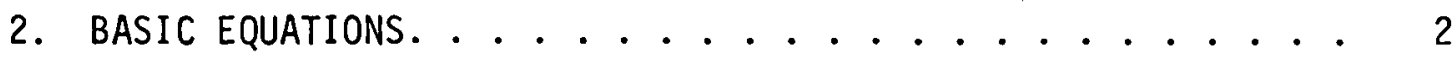

3. IMPURITY TREATMENT ..................... 4

4. RUNAWAY PHYSICS. . . . . . . . . . . . . . . 6

5. NUMERICAL RESULTS FOR NORMAL ORMAK DISCHARGES. ..... 11

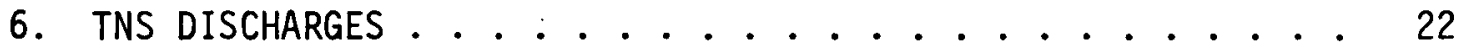

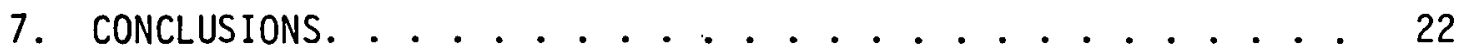

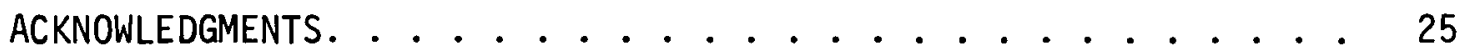

REFERENCES ..................... 25 
THIS PAGE

WAS INTENTIONALLY

LEFT BLANK 


\section{ABSTRACT}

A zero-dimensional tokamak start-up code is used to investigate the generation of runaway electrons in the Oak Ridge Tokamak (ORMAK) and The Next Step (TNS) and the effect of the runaways on the plasma breakdown, current, and energy balance. The runaways, which are considered collisionless, are treated self-consistently in the circuit equation by including a runaway current component (determined from a runaway rate equation). During the earliest stages of a discharge, the total current in the plasma is so low that closed flux surfaces do not exist. Runaways produced are lost almost instantiy because they follow magnetic field lines that intersect the limiter. Once the current in the tokamak builds up sufficiently, closed flux surfaces start forming which improves runaway containment. The time $\tau$ when this occurs is uncertain. Results on ORMAK and TNS are displayed for different values of $\tau$ (before which any runaway created is assumed to be lost instantaneously). The assumption of flux surface closure after some arbitrary time $\tau$ is then justified by modeling an ORMAK discharge which includes the effects on runaway confinement of error fields generated by currents flowing in the leads to the toroidal field coils. Also shown are ORMAK simulations in different density regimes and TNS results for different loop voltage pulses. 


\section{INTRODUCTION}

Most studies of the initiation of a discharge in a tokamak ${ }^{1-3}$ have either evaluated the current carried by the runaway component of the electron distribution function in a manner that is decoupled from the dynamic evolution of the plasma or neglected it altogether. A selfconsistent analysis of the start-up problem requires that the runaway current be included in the circuit equation. Its inclusion can then dynamically modify the way the plasma current evolves, which in turn influences the electron temperature. This influence can affect the plasma breakdown and the energy balance and, consequently, the conditions for. further runaway generation.

An attempt is made here to investigate the start-up phase of a tokamak operation with emphasis on the effects runaways have on the plasma current, formation, and energy balance. For this purpose, a very simple set of zero-dimensional, time-dependent, coupled rate equations for atomic hydrogen are solved numerically in conjunction with a circuit equation which contains a runaway term. Molecular physics processes are ignored and coronal equilibrium is assumed in the treatment of all impurities.

These equations are described in more detail in Sects. 2-4 and applied to model discharges in the Oak Ridge Tokamak (ORMAK) and The Next Step (TNS) in Sects. 5 and 6. ORMAK and TNS discharges are simulated for a set of different initial times early in each discharge (prior to which all magnetic field lines are considered to spiral out and strike the limiter, so any runaway created is assumed to be lost instantaneous $1 y)$. In addition, ORMAK simulations are carried out for different filling pressures, and therefore different final electron densities, and TNS discharges are modeled for different loop voltage pulses. 


\section{BASIC EQUATIONS}

The study in zero dimensions of the plasma evolution in a tokamak requires solving a set of coupled rate and circuit equations. The coupled rate equations examined here include simple versions of the ion, neutral atom, electron energy, and ion energy balance equations. The electron density is obtained from the condition of plasma quasi-neutrality.

The ion balance equation consists of an ionization rate term $\left(n_{e} n_{0}<\sigma v>\right)$ and a confinement loss rate term $\left(n_{i} / \tau_{p}\right)$

$d_{i t}^{i}=n_{e} n_{0}\langle\sigma v\rangle-n_{i} / t_{p}$,

where $n_{i}, n_{e}$, and $n_{0}$ are the proton, electron, and neutral atom densities, respectively, and $\tau_{p}$ is the particle confinement time. The neutral atom balance equation is composed of a loss rate due to ionization, a gas puff rate $g_{p}$, and a recycling rate off the toroidal chamber walls. It is assumed here that all ions lost to the walls are recycled back as cold neutral a toms;

$\frac{d n_{u}}{d t}=-n_{e} n_{0}\langle\sigma v\rangle+g_{p}+n_{i} / \tau_{p}$

The electron energy balance equation considered here can be written as

$3 \frac{d}{2} d t\left(n_{e} e_{e}\right)=n^{2}-n_{e} n_{0}<u v>U_{n}-\frac{3}{2} n_{e}^{T} e^{/ \tau} \varepsilon$

$$
\begin{aligned}
& +1.2 \times 10^{-18} n_{i} n_{e}\left(T_{i}-T_{e}\right) / T_{e}^{3 / 2} \\
& -3 \times 10^{-21} z_{e f f} n_{e}^{2} T_{e}^{1 / 2}-P_{z}-P_{i},
\end{aligned}
$$

which includes ohmic heating power $\left(n J^{2}\right)$, ionization power $\left(n n_{0}<\sigma v>U_{0}\right.$, $U_{0} \sim 20 \mathrm{eV}$ includes molecular dissociation, radiation, and ionization ${ }^{2}$ ), heat conduction to the walls ( $n_{e}^{\top} e^{/ \tau_{\varepsilon}}, \tau_{\varepsilon}=$ energy confinement time), 
ion electron energy transfer rate $\left[1.2 \times 10^{-18} n_{i} n_{e}\left(T_{i}-T_{e}\right) / T_{e}^{3 / 2}\right.$ in kiloelectron volts per cubic meter per second, where $T_{\mathfrak{i}}$ and $T_{e}$ are the ion and electron temperatures], bremsstrahlung radiation power loss $\left(3 \times 10^{-21} \mathrm{Z}_{\text {eff }} \mathrm{n}^{2} \mathrm{~T}^{1 / 2}\right.$ in kiloelectron volts per cubic meter per second), impurity line radiation power $\left(P_{z}\right)$, and impurity ionization power $\left(P_{j}\right)$.

The ion energy balance equation consists of the ion electron energy transfer rate and heat conduction to the walls,

$\frac{3}{2} \frac{d}{d t}\left(n_{i} T_{i}\right)=-1.8 \times 10^{-18} n_{i} n_{e}\left(T_{i}-T_{e}\right) / T_{e}^{3 / 2}-\frac{3}{2} n_{i} T_{i} / \tau_{\varepsilon} \cdot$

The circuit equation is modified to include the current component carried by runaways,

$L \frac{d I_{T}}{d t}=V-I_{P} R_{P}$,

where $I_{T}=I_{P}+I_{R}$. The runaways are considered to be colltsionless and hence perfectly conducting, so there is no resistivity associated with their motion. The resistance is $R_{p}=\left(2 R_{0} / a^{2} \varepsilon\right) n$, where $R_{0}=$ major radius, $a=$ minor radius, $\varepsilon=$ ellipticity of a cross-sectional cut of the tokamak, and $n=$ resistivity. The resistivity $n$ is given by

$n=A n_{s p}+n_{n}$

where $n_{s p}$ is the Spitzer resistivity for a $z_{\text {eff }}=1$ plasma $\left[\eta_{s p}=1.65\right.$ $\left.\times 10^{-9} / \mathrm{T}_{e}{ }^{3 / 2}(\Omega \mathrm{m}, \mathrm{keV})\right]$, and $A$ is the anomaly factor, ${ }^{4,5}$ introduced by the presence of impurities, which enhances the resistivity. For the sake of simplicity, one species of impurity (oxygen) is considered in modeling the plasma behavior in this analysis;

$$
\begin{aligned}
A=1 & +n_{z} / n_{e}\left\{z^{2}-z-z \ln z / \ln \Lambda\right. \\
& \left.+\left[\left(z_{t}^{2}-z^{2}\right) / 1 / \ln \Lambda\right] \ln \left[1+1.5 g^{4}\left(T_{e} / R y\right)^{2}\right]\right\},
\end{aligned}
$$

where $z$ is the average charge of the impurity ions, $n_{z}$ is the impurity density, $z_{t}$ is the total number of electrons per neutral impurity atom 
(8 for oxygen), $g=1.5\left(z_{t}-z\right)^{3 / 2 / 2} t$, in $\Lambda$ is the Coulomb logarithm and Ry is the Rydberg constant ( $R y \equiv 13.6 \mathrm{eV}$ ).

$\dot{n}_{n}$ is an effective resistivity introduced by electron neutral collisions which are dominant when the plasma is weakly ionized. In gas discharge experiments, the electron drift velocity is approximated by

$v_{D}=1.24 \times 10^{24} \mathrm{E} / \mathrm{n}_{\mathrm{o}}\left(\mathrm{m} / \mathrm{sec}, \mathrm{V} / \mathrm{m}, \mathrm{m}^{-3}\right)$.

The current density is $j=e_{e} v_{D}=E / n_{n}$; therefore, the neutral resistivity is

$n_{n}=5.04 \times 10^{-6} n_{0} / n_{e}$.

\section{IMPURITY TREATMENT}

As mentioned, oxygen is used to model all impurity behavior in the plasma. In addition, it is assumed that coronal equilibrium conditions exist and results obtained from the average ion mode ${ }^{6}$ are used to determine the average charge state $z$ of the oxygen. The average ion model replaces the fractional population of the different ionic states of an impurity with a fictitious average impurity ion.

The presence of a large impurity concentration when a plasma is still cold can extinguish a discharge by line radiation. For modeling tokamak discharges, a desorption model is used which assumes that all oxygen impurities are attached to the chamber walls at first and are desorbed linearly as a function of temperature once the plasma becomes sufficiently hot $(>50 \mathrm{eV})$. When $\mathrm{T}_{\mathrm{e}}$ exceeds $500 \mathrm{eV}$, it is assumed that all impurities have been cleared off the walls. The impurity density can then be written as

$$
n_{z}=\left\{\begin{array}{l}
0 \quad T_{e}<0.05 \mathrm{keV}, \\
n_{z t}\left[\left(T_{e}-0.05\right) / 0.45\right] \quad 0.05 \mathrm{keV}<T_{e}<0.5 \mathrm{keV}, \\
n_{z t} \quad T_{e}>0.5 \mathrm{keV} .
\end{array}\right.
$$


$n_{z t}$ is the total impurity density chosen to be desorbed into the plasma. With expressions for $z$ and $n_{z}$ obtained, the resistive anomaly factor $A$ can be determined.

Coronal equilibrium calculations for oxygen ${ }^{7}$ give the line radiation power as

$P_{z}=10^{-13} n_{e} n_{z} L_{z}\left(W / m^{3}\right)$,

where $L_{z}$ is expressed as a function of the electron temperature.

To obtain an expression for the ionization power of the oxygen impurities, some further simplifications are made. When $j<z<j+1$,

$$
\begin{aligned}
z=\sum_{k=1}^{8} k\left(n_{z}^{k} / n_{z}\right) & \simeq j\left(n_{z}^{j} / n_{z}\right)+(j+1)\left(n_{z}^{j+1} / n_{z}\right) \\
& \simeq j\left[\left(n_{z}-n_{z}^{j+1}\right) / n_{z}\right]+(j+1)\left(n_{z}^{j+1} / n_{z}\right) \\
& =j+\left(n_{z}^{j+1} / n_{z}\right),
\end{aligned}
$$

where $\left(n_{z}^{k} / n_{z}\right)$ is the fraction of the oxygen with charge state $k$. Similarly, an average ionization potential i can be written as

$$
\begin{aligned}
i=\sum_{k=1}^{8} i_{k}\left(n_{z}^{k} / n_{z}\right) & \simeq i_{j}\left(n_{z}^{j} / n_{z}\right)+i_{j+1}\left(n_{z}^{j+1} / n_{z}\right) \\
& \simeq i_{j}+\left(i_{j+1}-i_{j}\right)\left(n_{z}^{j+1} / n_{z}\right),
\end{aligned}
$$

where $i_{k}$ is the ionization potential of the $k^{\text {th }}$ oxygen state.

The oxygen ionization power is approximated by

$P_{i} \simeq I_{p} \frac{d n_{z}}{d t}+n_{z} \frac{d i}{d t}$

The first term represents the power required to get the oxygen stripped off the chamber walls to the average charge state $z$. The second term is the impurity density times the rate of change of the average ionization potential. For an average charge $z$, 
$I_{p}=\sum_{k=1}^{j} i_{k}+i_{j+1}\left(n_{z}^{j+1} / n_{z}\right)$

From Eqs: (12), (13), and (15), one can obtain expressions for $i$ and $I_{p}$ as functions of $z$ so that Eq. (14) for $j<z<j+1$ is

$P_{i}=\left[\sum_{k=1}^{j} i_{k}+i_{j+1}(z-j)\right] \frac{d n_{z}}{d t}+n_{z}\left(i_{j+1}-i_{j}\right) \frac{d z}{d t}$,

where $z$ and $\mathrm{dz} / \mathrm{dt}$ are obtained from results of coruld equilibrium calculations. 6

The rough approximations made to obtain an expression for the oxygen ionization power may not have a very great impact because the 1 ine radiation power $P_{z}$ is a more dominant term in the electron energy balance equation. During the steady-state portion of a discharge the assumption of coronal equilibrium is relatively good, but unfortunately this approximation is not too reliable during the plasma breakdown phase.

\section{RUNAWAY PHYSICS}

The equation of motion of an electron in an electric field is given by

$\frac{d p}{d t}=e \underline{E}-m \underline{w}$,

where acceleration of the electron by the field $\underline{E}$ is balanced by the drag caused by coulomb collisions. The electron-electrun cullision frequency is

$v_{e e}(v)=\left(4 r e^{1} n_{e} / m^{2} v^{3}\right) \ln \Lambda$,

where $e$ is the electron charge, $n_{e}$ the electron density, $m$ the electron mass, in $\Lambda$ the coulomb logarithm, and $v$ the electron velocity. The collision frequency decreases with increasing electron velocity. This implies that above a certain critical velocity given by 
$v_{c}^{2}=\left(4 \pi e^{3} n_{e} / m E\right) \ln \Lambda$,

the electron is continuously accelerated to even higher energies as eE becomes larger than mvv in Eq. (17). A runaway electron is that which has a velocity greater than $\underline{v}_{c}$.

The electric field required for the critical velocity to be equal to the thermal velocity is defined as the Dreicer field and is given by

$E_{D}=\left(4 \pi e^{3} n_{e} / m v_{t h}^{2}\right) \ln \Lambda$

In this analysis it is considered that all electrons, once they run away, are essentially collisionless. Only if they strike the limiter of the toroidal chamber are they assumed to be lost from the runaway distribution. In addition, the effects of microturbulence are neglected.

The orbit shift mode ${ }^{8}$ is used to determine the confinement of runaways in a tokamak. It is based on the principle of conservation of angular momentum of the particles in the device, i.e..,

$P_{\phi}=\gamma m_{0} v_{\phi} R-\frac{e_{R A}}{c} R A_{\phi}=p R-\frac{e}{c} \psi$,

where

$R=R_{0}+r \cos \theta$.

For an approximately type-B current profile $\left\{j(r) \simeq J_{0}\left[1-(r / a)^{3}\right]\right\}$, the flux function $\psi$ is in Gaussian units for $r<a$,

$\psi(r)=\int_{0}^{r} B_{\theta} R d r \simeq \frac{5}{6}\left(\pi R_{0} I_{T} / \varepsilon E c\right)(r / a)^{2}\left[1-(4 / 25)(r / a)^{3}\right]$,

where

$R_{0}=$ major radius

$\mathrm{a}=$ minor radius

$\varepsilon=$ ellipticity of a cross-sectional cut of the tokamak

$E=$ complete elliptical integral of the first kind

$I_{T}=$ total current

$c=$ speed of 1 ight. 
Neglecting $(4 / 25)(r / a)^{3}$ and writing $r^{2}=\left(R-R_{0}\right)^{2}+y^{2}$, the canonical angular momentum is

$P_{\phi} \simeq-\frac{5}{6}\left(\pi R_{0} I_{T} e / \varepsilon E a^{2} c^{2}\right)\left[\left(R-R_{O}-\frac{3}{5} \frac{\varepsilon E a^{2} c^{2}}{\pi R_{0} I T^{e}} p\right)^{2}+y^{2}-\left(\frac{3}{5} \frac{\varepsilon E a^{2} c^{2}}{\pi R_{0} I_{T} T^{e}}\right)^{2}\right]$.

Because $P_{\phi}$ is a constant over the orbit of a particle, this equation represents a circle shifted outward in major radius.

The magnitude of the orbit shift of a runaway is proportional to its momentum and inversely proportional to the total current,

$\Delta=\frac{j}{5}\left(\varepsilon E a^{2} c^{2} / \pi R_{0} e\right)\left(p / I_{T}\right)$

A runaway born on a certain orbit gains energy from the electric field and shifts outward until it strikes the limiter.

In this zero-dimensional analysis, it is assumed that on the average, a11 runaways born in a tokamak are confined if their orbit shifts are less than half the minor radius, and that they strike the limiter once, $\Delta=$ $a / 2$. One can then obtain from Eq. (24) an expression for the maximum momentum a runaway can have and still remain contained,

$P_{\max }=\frac{5}{6}\left(\pi R_{0} c / \varepsilon E c^{2} a\right) I_{T}$.

Because electrons are essentially collisionless once they run away, the equation of motion of an electron that becomes a runaway at time $t_{1}$ can be integrated to

$p=p_{c}\left(t_{1}\right)+\int_{t_{1}}^{t} e E d t^{-}$,

where $p_{c}\left(t_{j}\right)$ is the critical momentum $\left(p_{c}=\gamma m_{0} v_{c}\right)$. All runaways born at $t_{1}$ have the same momentum $p$ at any time $t \geqslant t_{1}$. This is more clearly illustrated in Fig. 1 . All runaways created at time $t_{1}$ are arcelerated by the electric field until $t=t_{2}$ when their momenta $p=p_{\max }$. At this time their orbits have shifted by half the minor radius and therefore are considered to be striking the limiter. At any given time, the runaway population rate of change is 
$\frac{d N}{d t}=\left[S_{R}(t)-L\left(p_{\max }\right)\right] V_{T}$,

where

$$
\begin{aligned}
& S_{R}(t)=c_{1} n_{e} v_{\text {ee }}\left(v_{\text {th }}\right)\left(\frac{E}{E_{D}}\right)^{-\frac{3}{16}\left(z_{\text {eff }}+1\right)} \\
& \exp \left\{-\frac{E_{D}}{4 E}-\left[\left(1+z_{\text {eff }}\right) \frac{E_{D}}{E}\right]^{1 / 2}\right\} \\
& \times \exp \left\{-\frac{T_{e}}{m_{0} c^{2}}\left[\frac{1}{8}\left(\frac{E_{D}}{E}\right)^{2}+\frac{2}{3}\left(\frac{E_{D}}{E}\right)^{3 / 2}\left(1+z_{\text {eff }}\right)^{1 / 2}\right]\right\}
\end{aligned}
$$

is the runaway creation rate, 9

the constant $c_{1}=0.35$ (Ref. 10),

$v_{\text {th }}=\sqrt{T_{e} / m_{0}}$,

$z_{\text {eff }} \equiv\left(n_{i}+z^{2} n_{z}\right) / n_{e}$,

$\mathrm{V}_{\mathrm{T}}=$ toroidal chamber volume, and

$L\left(p_{\max }\right)=$ loss rate of runaways whose momenta $p=p_{\max }$ at time $t$.

As illustrated in Fig. 1, these runaways were all created at some earlier time $t_{0}$, so in essence

$L\left(P_{\max }\right) \simeq S_{R}\left(t_{0}\right)$

If the runaway velncity is taken to be approximately $c$, the runaway current is $I_{R}=e\left(\pi a^{2} \varepsilon\right) n_{R} c$, so the rate of change of runaway current is

$$
\frac{d I_{R}}{d t}=e c \pi a^{2} \varepsilon\left[S_{R}(t)-S_{R}\left(t_{0}\right)\right] \text {. }
$$

The determination of $t_{0}$ is done by numerically solving Eq. (26) for $p=$ $p_{\max }$ at each time step. This requires keeping track of $p_{c}(t)$ and $\int_{0}^{t_{j}}$ eEdt' at each step $j$. One must also keep track at each time step of all the variables that contribute to the runaway creation rate $S_{R}$. If 


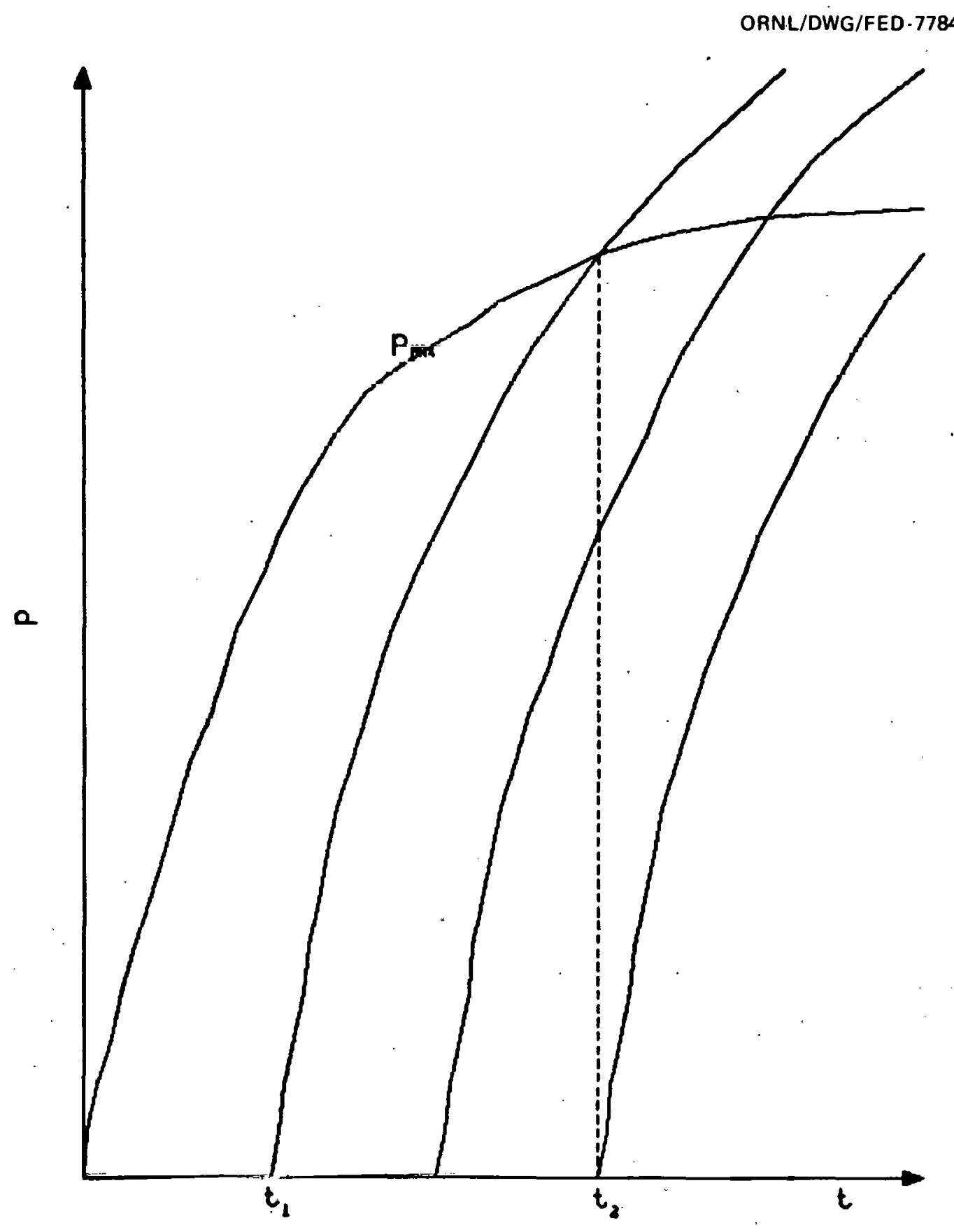

Fig. 1. When the momentum $p$ of a runaway exceeds $p_{\text {MAX }}$, it strikes the 1imlter. 
$t_{0}$ falls between $t_{k}$ and $t_{k+1}$, then the value of each variable at $t_{0}$ is determined by a linear interpolation of its values at $t_{k}$ and $t_{k+l}$.

The circuit equation is solved (in conjunction with the coupled rate equations) using Eq. (30) for the rate of change of runaway current. The runaway creation rate used is only approximate, as Eq. (28) is obtained from a quasi-steady-state solution of the Fokker-Planck equation. A more accurate treatment of this problem would require solving the very complex, fully time-dependent kinetic equation for the runaway production rates.

\section{NUMERICAL RESULTS FOR NORMAL ORMAK DISCHARGES}

An Ordinary Differential Equation (ODE) solverll is used to solve the coupled rate and circuit equations. A typical loop voltage for a normal ORMAK discharge is shown in Fig. 2 and consists of a capacitor-driven component during the first $15 \mathrm{msec}$ and a battery-driven component of $\sim 2.4$ $V$ from then on. ORMAK parameters are $R_{0}=0.8 \mathrm{~m}, a=0.23 \mathrm{~m}, B_{T}=2.5$ $T$; and $l_{1}=1.5$, where $l_{f}$ is the internal self-inductance. The initial conditions chosen are $T_{j}=0.05 \mathrm{eV}, T_{e}=2 \mathrm{eV}$, and $n_{e}=10^{16} \mathrm{~m}^{-3}$. The energy confinement time ${ }^{12}$ is $\tau_{\varepsilon}=10^{-21} \mathrm{n}_{e} \sqrt{9 / \mathrm{eff}_{\mathrm{ef}}} / 3\left(\mathrm{sec}, \mathrm{m}^{-3}\right)$ and the particle confinement time is chosen to be $\tau_{p}=3 \tau_{\varepsilon}$. To minimize numerical difficulties, $\tau_{\varepsilon}$ is not allowed to be less than about $2 \mathrm{msec}$.

The equations are first solved for a filling pressure of $1.35 \times 10^{-4}$ torr $\left(\sim 9 \times 10^{18}\right.$ neutral atoms $\left./ \mathrm{m}^{3}\right)$. A smaller filling pressure is required to obtain a certain final electron density, as it is inherent in a zerodimensional analysis that the plasma does not screen out the neutral atoms. It is assumed that runaway electrons get scraped off at the limiter only if their orbits shift by at least half the minor radius. No other loss mechanism is taken into consideration. The evolution of densities and currents is shown in Fig. 3. The plasma does not break down at all and virtually all the current is carried by the runaways. The input power is almost totally deposited in the runaway component of the electron distribution function. It appears that because the runaways are so well confined at early times, the discharge becomes runaway-dominated at the expense of the plasma current. 


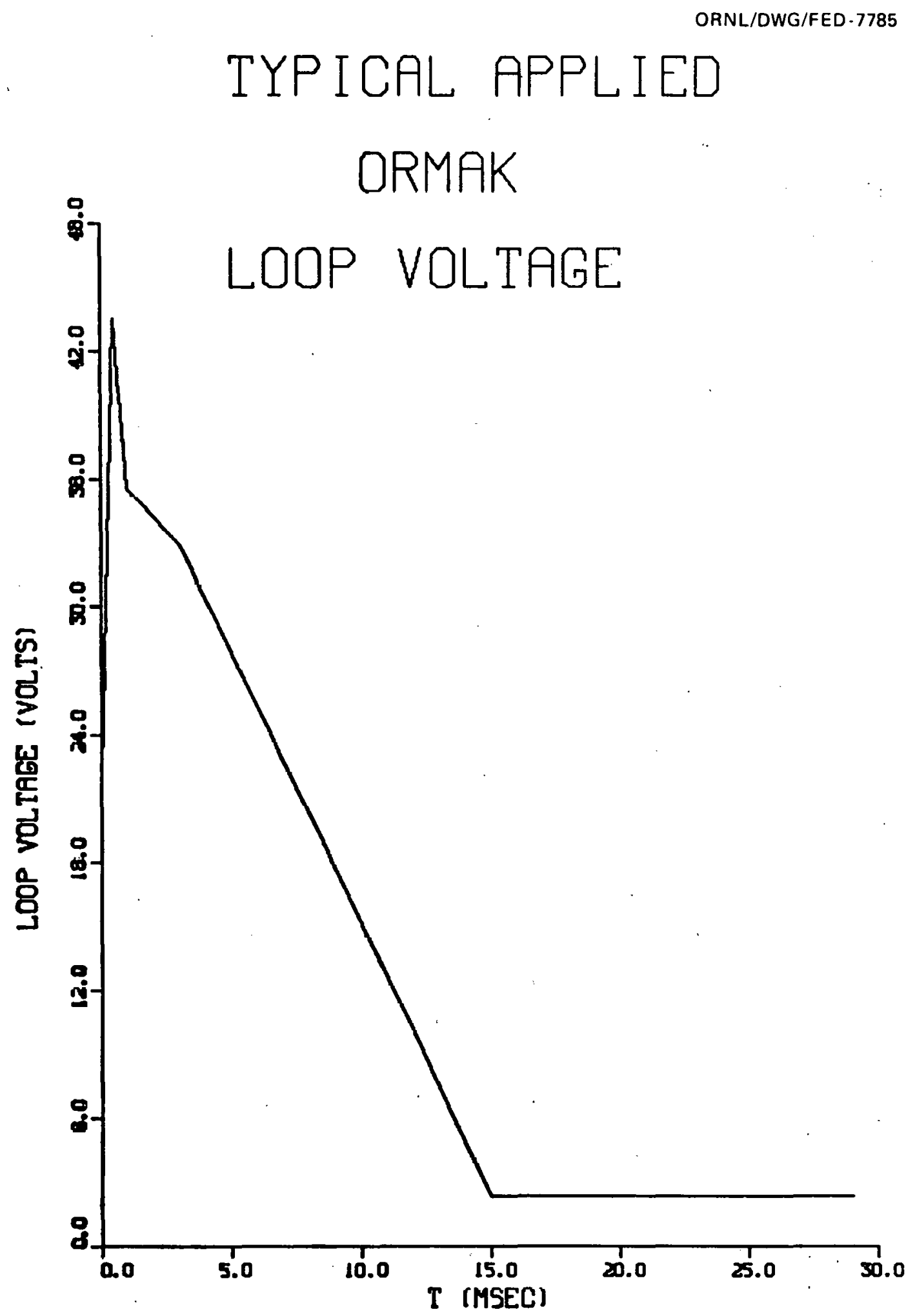

Fig. 2. Typical applied ORMAK loop voltage. 

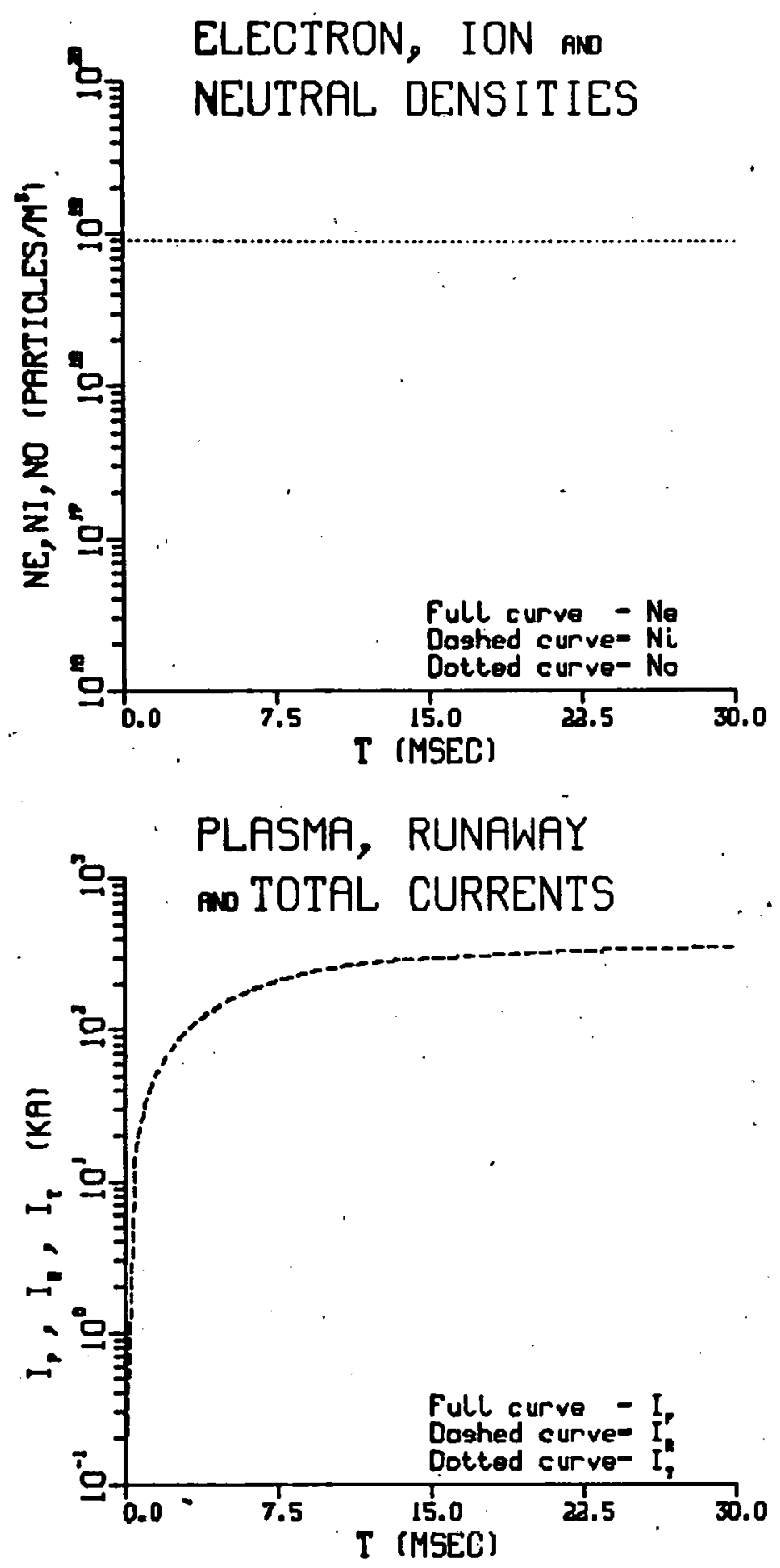

Fig. 3. Filling pressure $p=1.35 \times 10^{-4}$ torr. 
To obtain simulations that are in better agreement with experimentally observed normal discharges (which break down in the first few milliseconds and carry only about 1 kA of runaway current), additional loss mechanisms for runaway electrons must be considered. One to be discussed in further detail later is that the magnetic field structure can exhibit inhomogeneities during the very early stages of a discharge, which allows runaways to be lost instantaneously by following field lines that strike the limiter. Another possible explanation that could account for a poorer runaway confinement at early times is the existence of a skin effect, which would imply that most runaways created early arc located near the plasma edge. Then the condition that runaways are lost only if the shifts of their orbits are greater than half the minor radius beculles too restrictive.

Figure 4 shows the effect on plasma and runaway currents when all runaways created before a time $\tau$ are considered to be lost instantaneous1y. For $\tau=20 \mu \mathrm{sec}$, the plasma and runaway currents are comparable in magnitude after $10 \mathrm{msec}$. The $\tau=200 \mu \mathrm{sec}$ simulation appears to give relatively good agreement with experiments with $I_{P} \sim 200 \mathrm{kA}$ and $I_{R} \sim 2 \mathrm{kA}$. A good confinement of runaways during the early stages of a discharge results in a high runaway current as well as a delayed rise of the plasma current and consequently a delayed breakdown.

The evolutions of runaway currents for different filling pressures, and hence different steady-state electron densities, are shown in Fig. 5 for the case when all runaways created in the first $200 \mu \mathrm{sec}$ are considered to be lost instantaneously. At high density all runaways are created prior to breakdown, while at low density most runaways are produced after the $\mathrm{plasma} \mathrm{has} \mathrm{ionized.} \mathrm{The} \mathrm{rurlaway} \mathrm{creation} \mathrm{rate} S_{R}$ is proportional to $\exp \left[-1 / 4\left(E_{D} / E\right)-\sqrt{\left.\left(1+Z_{e f f}\right) / E_{D} / E\right]}\right.$. When the plasma is weakly ionized, $E / E_{D} \propto\left(I_{p} T_{e} n_{0}\right) / n_{c}^{2}$, so for comparable $I_{p}, T_{e}$, and $n_{e}$, a higher fliling pressure implies a higher $E / E_{D}$ and hence a greater production rate. But once the plasma ionizes, $E / E_{D}$ scales as $\left(Z_{e f f} I_{p}\right) /\left(T_{e}^{1 / 2} n_{e}\right)$. The dominant difference in $E / E_{D}$ between high density and low density simulations comes from $n_{e}$. Therefore, the lower the final electron density, the larger the creation rate. All this accounts for the fact that the runaway current in the low density simulation tends to be smaller prior to breakdown but 

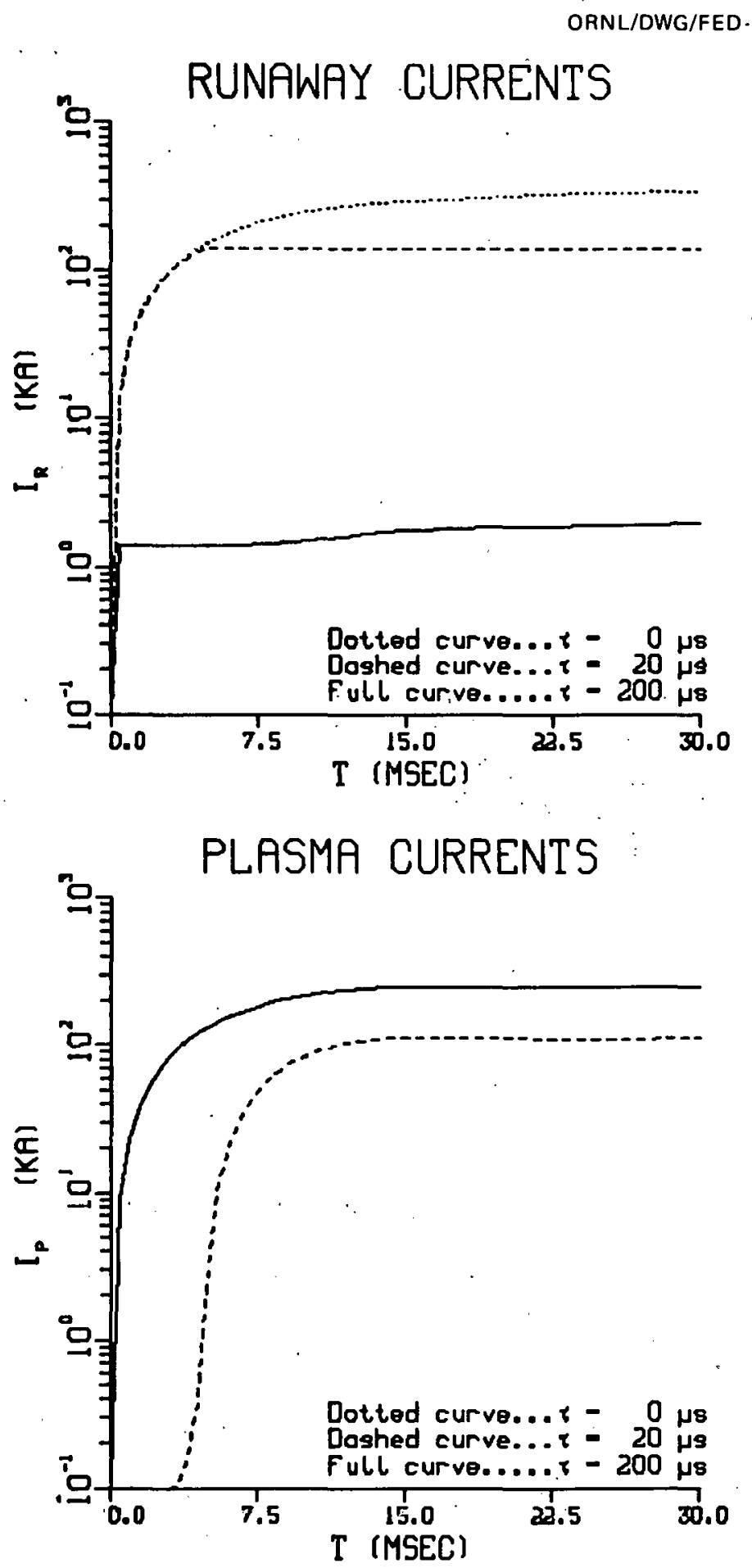

Fig. 4. Filling pressure $p=1.35 \times 10^{-4}$ torr. The impurity fraction is 0.1675 . 


\section{RUNAWAY CURRENTS}

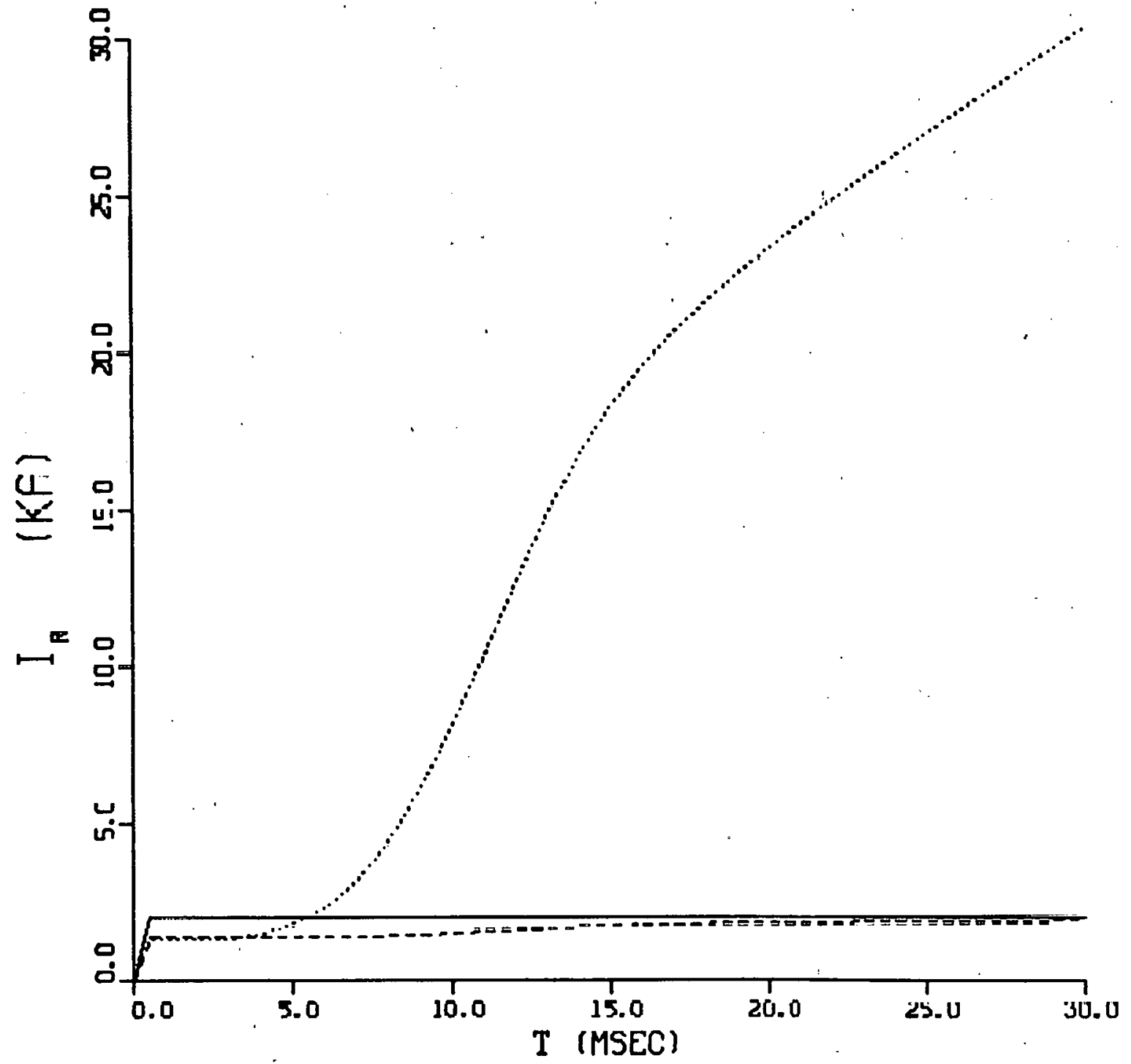

Fig. 3. Uotted curve: $n_{0}=6.0 \times 10^{18}$ neutral atoms $/ \mathrm{m}^{3}$; dashed curve: $n_{0}=9.0 \times 10^{18}$ neutral atoms $/ \mathrm{m}^{3}$; solid curve: $n_{0}=1.8 \times 10^{19}$ neutral atoms $/ \mathrm{m}^{3}$. All runaways born prior to $\tau=200 \mu \mathrm{sec}$ are assumed 1ost. The impurity rraction is 0.1675 . 
increases afterwards, while runaways in the high density simulations are born only when the gas is weakly ionized.

To 11 lustrate the effect a typical magnetic field inhomogeneity has on runaway containment in a tokamak, a modified flux function developed by J. A. Rome ${ }^{13}$ for ORMAK that includes a contribution from the currents flowing in the leads to the toroidal field coils is examined:

$$
\left.\psi(x, y)=\mid \begin{array}{l}
\frac{\mu_{0} N_{L} I_{L} b_{L}}{4 \pi^{2} R_{0}} \ln \left[\frac{\left(x-r_{L}-a_{L}\right)^{2}+y^{2}}{\left(x-r_{L}+a_{L}\right)^{2}+y^{2}}\right. \\
-\frac{\mu_{0} I_{T}}{4 \pi a^{2}}\left(x^{2}+y^{2}\right)=\psi_{1}-\psi_{0},
\end{array}\right]
$$

where

$I_{L}=$ current in leads to the toroidal field coils

$\mathrm{N}_{\mathrm{L}}=$ number of toroidal field coils $=56$

$b_{L}=$ width of error coil $=0.015 \mathrm{~m}$.

$a_{L}=$ length of error coil $=0.09 \mathrm{~m}$

$r_{L}=$ distance between toroidal chamber and error coil loop center $=$ $0.455 \mathrm{~m}$

$\psi_{1}=$ flux due to error coils

$\psi_{0}=$ flux due to the total current in the plasma.

$I_{T}$ is the total current in the plasma, $R_{0}$ the major radius, and a the minor radius. This flux function is applicable at the early stages of an ORMAK discharge when the current density can be assumed to have a somewhat flat profile.

When $\psi_{1} \ll \psi_{0}$, the flux surfaces form concentric tori in the chamber. However, early in a discharge $\psi_{1}$ can be of the same order as $\psi_{0}$ and all (or at least a significant portion) of the magnetic field lines can spiral out and strike the limiter. Consequently, most runaways born at this time are lost almost instantly. As the plasma current builds up, closed flux surfaces start forming and runaways begin to be confined. When the toroidal field and current are parallel, the largest flux surface contained strikes the outer limiter at the midplane of the torus ${ }^{13}$ (at the inner limiter when the fleld and current are antiparallel). Using 
Eq. (31), one can evaluate the flux at the outer limiter (at $x=a, y=0$ ) and then evaluate the other position at the midplane of the torus which gives the same $\psi$. That determines the size of the largest contained flux surface. With the assumption that this flux surface has roughly the same shape as the tokamak cross section, all runaways created within its volume are considered to be contained, while those born outside are assumed to strike the limiter immediately after their birth without contributing to the runaway current.

Since the runaways are contained in only part of the toroidal chamber volume, the expression for $I_{R}$ and hence $d I_{R} / d t$ must be slightly modified:

$I_{R}=\frac{e c \pi a^{2} \varepsilon}{V_{T}} N=\frac{e c}{2 \pi R_{0}} N$,

where $N$ is the total number of runaways in the torus.

Therefore,

$\frac{d I}{d t}=\frac{e c}{2 \pi R_{0}} \frac{d N}{d t}$

and

$\frac{d N}{d t}=$ creation rate - loss rate

$$
=\frac{d\left(n_{R} V\right)}{d t}-\left.\frac{d N}{d t}\right|_{\text {ross }}
$$

The rate of runaways being lost at time $t$ is equal to their creation rate at an earlier time $t_{0}$, i.e.,

$\left.\frac{d N}{d t}\right|_{\text {loss }}=\left.\frac{d N_{0}}{d t_{0}}\right|_{\text {creation }}-\frac{d}{d t_{0}}\left[n_{R}\left(t_{0}\right) v\left(t_{0}\right)\right]$.

Equation (34) then becomes 


$$
\begin{aligned}
\frac{d N}{d t} & =\frac{d}{d t}\left(n_{R} V\right)-\frac{d}{d t_{0}}\left[n_{R}\left(t_{0}\right) V\left(t_{0}\right)\right] \\
& =V S_{R}+n_{R} \frac{d V}{d t}-V_{0} S_{R_{0}}-n_{R_{0}} \frac{d V_{0}}{d t_{0}} \\
& \simeq V S_{R}-V_{0} S_{R_{0}},
\end{aligned}
$$

where the volumes $V_{T}, v$, and $v_{0}$ are illustrated in Fig. 6 and $S_{R_{0}}=$ $S_{R}\left(t_{0}\right)$. The term $n_{R} \frac{d V}{d t}\left(n_{R_{0}} \frac{d V_{0}}{d t_{0}}\right)$ corresponds to the rate of volume increase of the largest contained flux surface times the density of runaways in the incremental volume at time $t\left(t_{0}\right)$. This density is very small, as all runaways created (in the incremental volume) prior to containment are assumed to be instantaneously lost. So $n_{R} d V / d t\left(n_{R_{0}} d V_{0} /\right.$ $\left.d t_{0}\right)$ is neglected compared to $V_{S_{R}}\left(V_{0} S_{R_{0}}\right)$. Then

$$
\frac{d I}{d t}=\frac{e c}{2 \pi R_{0}}\left(V S_{R}-V_{0} S_{R_{0}}\right)
$$

The coupled rate equations and the circuit equation are then solved using Eq. (37) for the rate of change of runaway current. A current $I_{L}=9 \mathrm{kA}$ flowing in the toroidal field coils gives $B_{T} \simeq 2 T$ on axis. The initial conditions and parameters are otherwise the same as those chosen in the results of Fig. 3. The evolution of densities and currents is shown in Fig. 7. The plasma breaks down within a millisecond, and at steady state $I_{P}>200 \mathrm{kA}$ and $I_{R} \sim 1 \mathrm{kA}$. This simulation is in good agreement with experiments and with the $\tau=200 \mu \mathrm{sec}$ simulation of Fig. 4 . During the early stages of the discharge the field lines hit the limiter so there is no runaway bulldup. This allows enough of a plasma current and breakdown to develop before the runaways created start to be contained. In this case the effect of runaways is not as crucial as if they were well confined from the very beginning of the discharge. 
ORNL/DWG/FED 7789
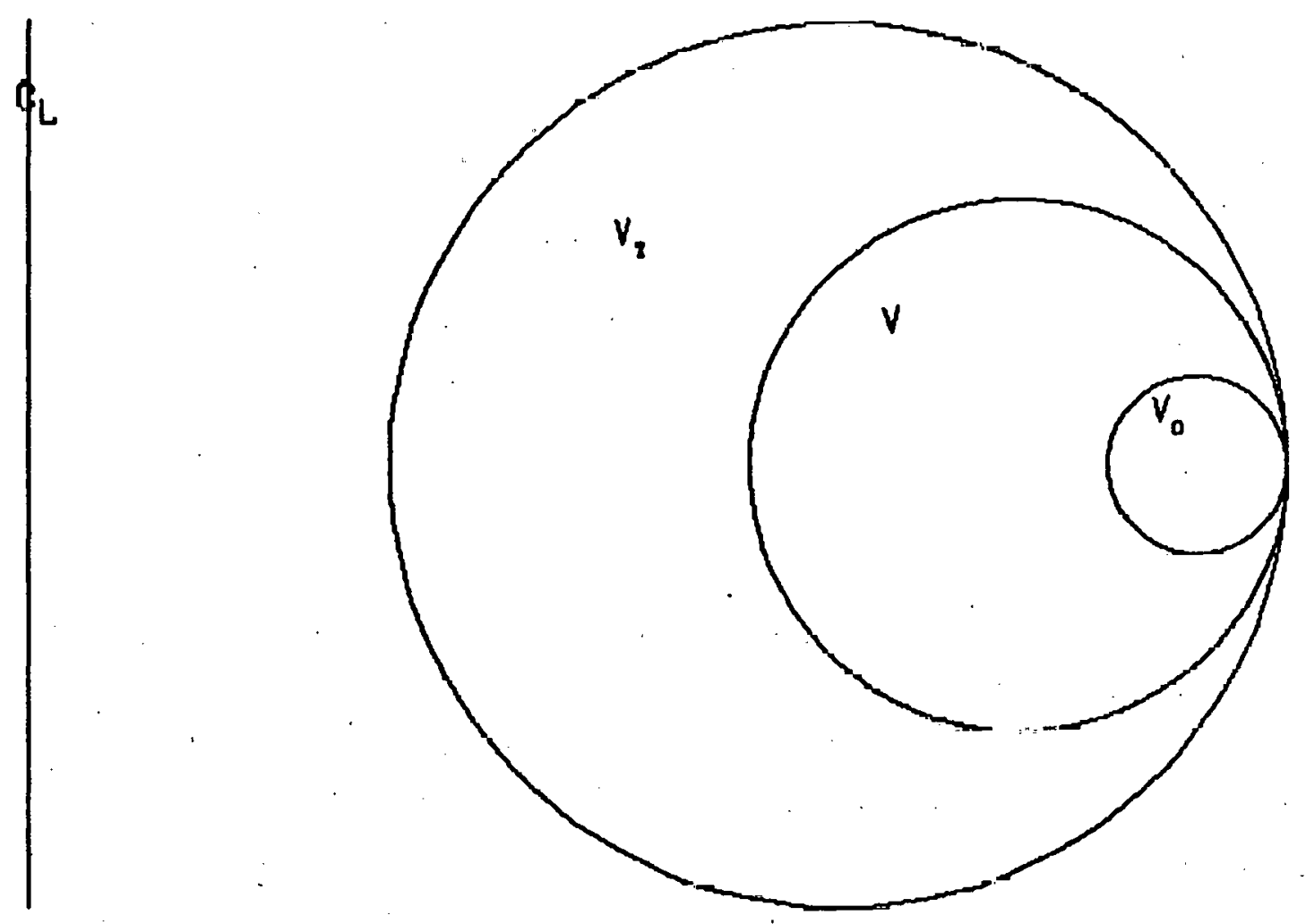

Fig. 6. $V_{r}=$ toroidal chamber volume; $V=$ vulume of largèst contained flux surfaces at time $t ; v_{0}=$ volume of largest contained flux surface at time $t_{0}<t$. 
ORNL/DWG/FED-7790
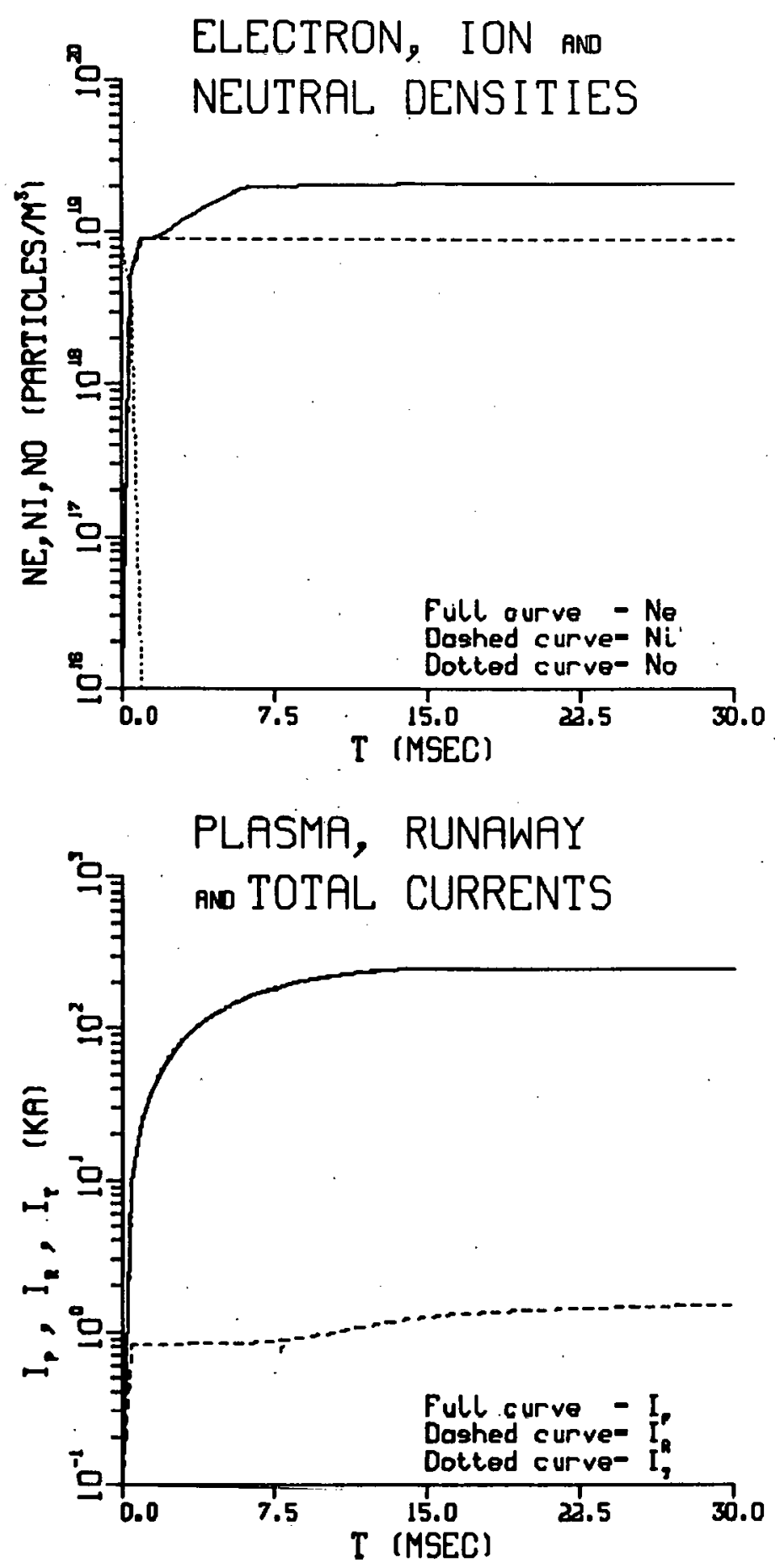

Fig. 7. $I_{L}=9 \mathrm{kA} ; \mathrm{p}=1.35 \times 10^{-4}$ torr. 


\section{TINS DISCHARGES}

The parameters for the TNS tokamak are $R_{0}=5 \mathrm{~m}, a=1.25 \mathrm{~m}, \varepsilon=$ $1.6, \mathrm{~B}_{\mathrm{T}}=4.3 \mathrm{~T}$, and $l_{j}=1.21$. The initial conditions chosen are $\mathrm{T}_{\mathrm{i}}=$ $0.5 \mathrm{eV}, T_{e}=5 \mathrm{eV}, n_{e}=10^{16} \mathrm{~m}^{-3}$, and $n_{0}=2 \times 10^{19} \mathrm{~m}^{-3}$. The energy confinement time is $1 \mathrm{sec}$ and the particle confinement time is $3 \mathrm{sec}$.

The voltage pulse is chosen to rise at a rate of $100 \mathrm{v} / \mathrm{msec}$ until it reaches $500 \mathrm{~V}$, where it remains until the plasma is formed (i.e., when sufficient ionization has occurred that the ion density exceeds the neutral atom density by a factor of 100). After that, the voltage is decreased to $50 \mathrm{~V}$ at the rate of $100 \mathrm{~V} / \mathrm{msec}$. Discharges are simulated for a set of different initial times from 0 to $1 \mathrm{msec}$, before which all runaways created are considered to be lost instantanenusly. As shown in Fig. 8, the earlier confinement of runaways results in a larger runaway current and a delayed plasma formation.

The set of discharges simulated in Fig. 9 assume that all runaways produced prior to $0.5 \mathrm{msec}$ are lost instantly. The runaway current at breakdown and the time of plasma formation are shown for different voltage pulses. The rates of voltage increase and decrease are kept the same as in the previous figure, but the maximum voltage is allowed to vary from 100 to $1000 \mathrm{~V}$. Lower voltages produce a smaller runaway current but have greater difficulty in ionizing the plasma.

In the simulations in Figs. 8 and 9 , once the plasma breaks down, the electron density is sufficiently high that no further punaways are produced.

\section{CONC.I UISSIONS}

A more appropriate modeling of the behavior of impurities in the plasma would require solving the nonequilibrium oxygen state coupled rate equations rather than assuming coronal equilibrium. In large tokamaks in particular, the skin effect may be important, so a one-dimensional analysis may give more realistic results for the runaway generation and $i$ ts effect on the plasma formation. 
RUNAWAY CURRENT

and

BREAKDOWN TIME

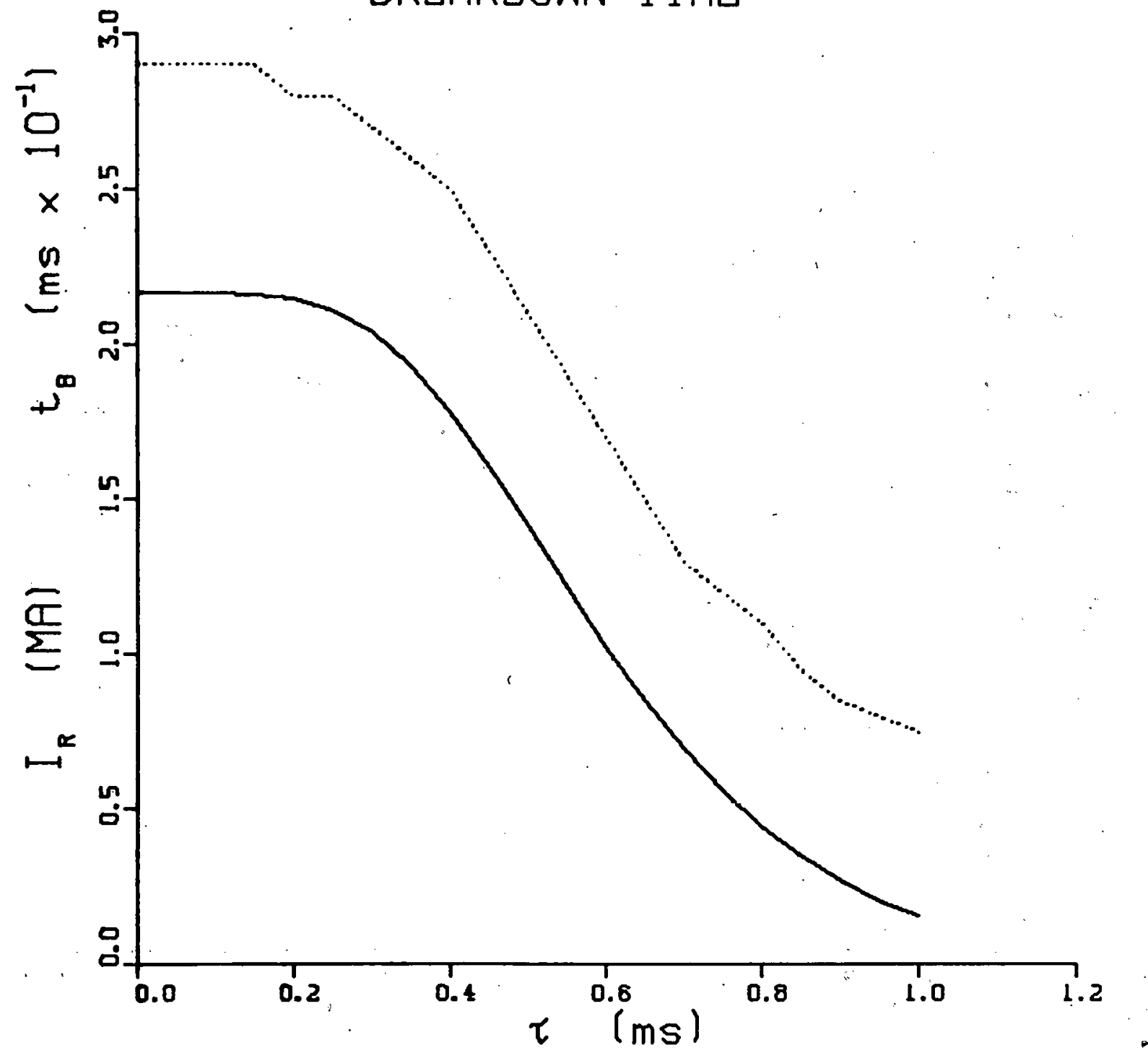

Fig. 8. All runaways born prior to $\tau$ are assumed instantly lost. $V_{\text {MAX }}=500 \mathrm{~V}$. Solid curve: $I_{R}$; dotted curve: $t_{B}$. 
ORNL/DWG/FED-7792

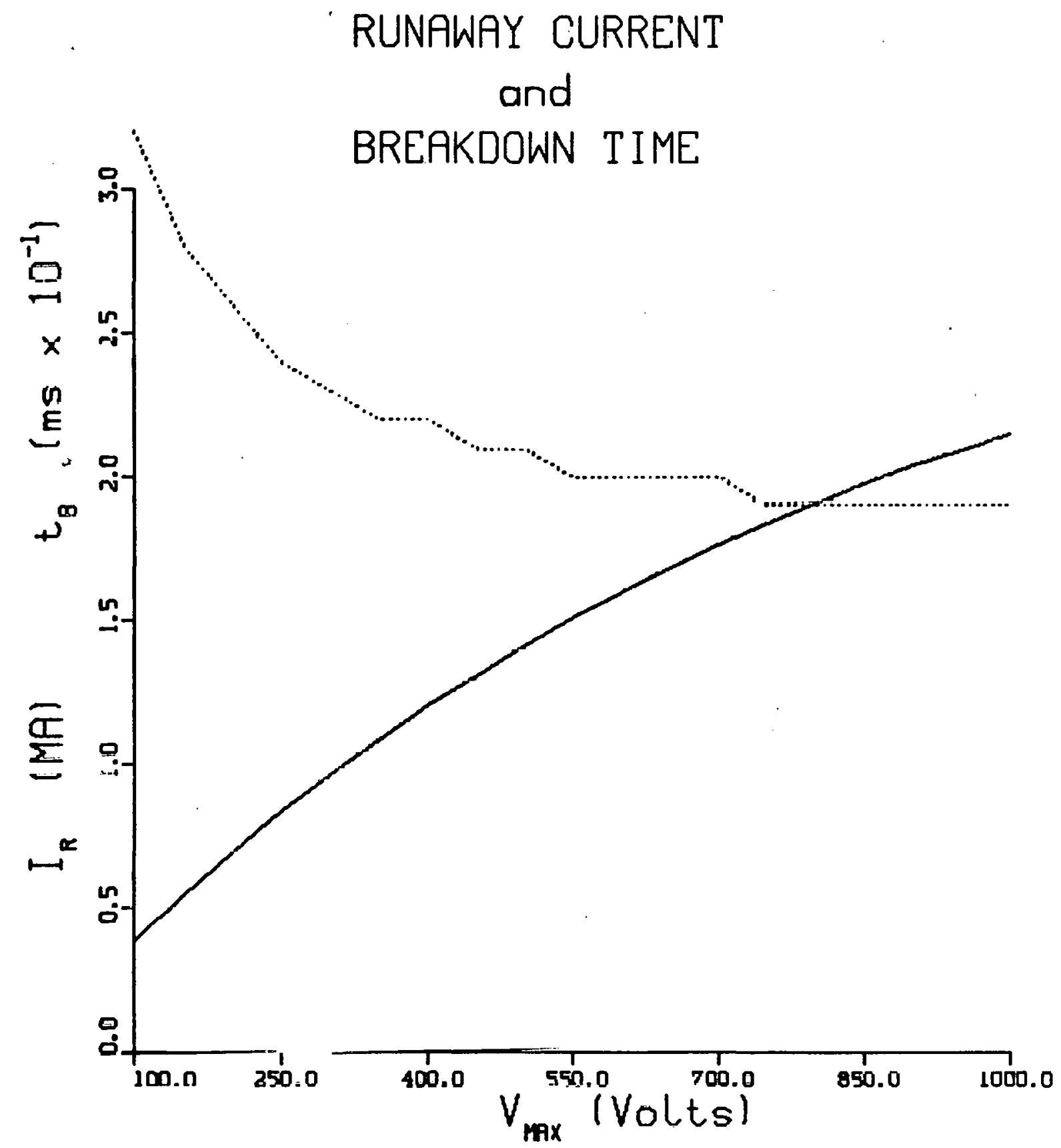

Fig. 9. All runaways born prior to $\tau=0.5 \mathrm{msec}$ are assumed instantly lost. Solid curve: $I_{R}$; dotted curve: $t_{B}$. 
In general, a good confinement of runaways during the early stages of a discharge results in a high runaway current and a delayed plasma breakdown. In high density regimes, runaways are generated prior to bulk ionization while in. low density regimes most runaways are formed after the plasma breakdown. This agrees qualitatively with ORMAK experimental evidence. 14 Finally, higher applied loop voltages for TNS achieve a faster plasma formation but are accompanied by larger runaway currents.

\section{ACKNOWLEDGMENTS}

One of the authors (A.C.) wishes to thank S. J. Zweben for many valuable discussions and helpful suggestions. Useful advice by $D$. A. spong is also appreciated.

\section{REFERENCES}

1. F. B. Marcus and S. E. Attenberger, Buil1. Am. Phys. Soc. 21,1125 (1976).

2. R. J. Hawryluk and J. A. Schmidt, Effects of Low Z Impurities during the Startup Phase of a Large Tokamak, MATT-1201, Princeton P1asma Physics Laboratory, Princeton, New Jersey (1976).

3. R. Papoular, The Genesis of Toroidal Discharges, EUR-CEA-FC-769, CEA Centre d'Etudes Nucleaires de Fontenay-aux-Roses, France (1975).

4. V. D. Kirillov, B. A. Trubnikow, and S. A. Trushin, Fiz. Plasmy (Sov. J. Plasma Phys.) 1, 117 (1975).

5. D. L. Shaeffer, Impurity Electron Core Effect in ORMAK, ORNL/TM5745, Oak Ridge National Laboratory, Oak Ridge, Tennessee (1977).

6. D. E. Post, (Princeton Plasma Physics Laboratory), private communication.

7. R. V. Jensen, D. E. Post et a1., Calculations of Impurity Radiation and Its Effects on Tokamak Experiments, PPPL-1334, Princeton Plasma Physics Laboratory, Princeton, New Jersey (1977).

8. D. A. Spong, Equilibrium, Confinement, and Stability of Runaway Electrons in Tokamaks, ORNL/TM-5147, Oak Ridge National Laboratory, Oak Ridge, Tennessee (March 1976). 
9. J. W. Connor and R. J. Hastie, Nucl. Fusion 15, 415 (1975).

10. R. M. Kuisrud, Y. C. Sun et al., Phys. Rev. Lett. 31, 690 (1973).

11. L. F. Shampine and M. K. Gordon, Computer Solvition of Ordinary Differential Equations: The Initial Value Problem, W. H. Freeman \& Co., San Francisco, California, 1975.

12. L. A. Berry et a1., Plasma Physics and Controlled Nuclear Fusion Research 1976, Vol. 1, p. 49 (1977).

13. J. A. Rome, Effects of Magnetic Field Errors in ORMAK, ORNL/TM-3880, Oak Ridge National Laboratory, Oak Ridge, Tennessee (June 1972).

14. H. Knoepfel and S. J. Zweben, Phys. Rev. Lett. 35,1340 (1975). 
ORNL/TM-5905

INTERNAL DISTRIBUTION

1. L. A. Berry

2. C. E. Bush

3. J. D. Callen

4. J. F. Clarke

5. R. J. Colchin

6-15. A. Cooper

16. E. C. Crume

17. J. L. Dunlap

18. A. C. England

19. J. T. Hogan

20. W. A. Houlberg

21. H. C. Howe

22. R. C. Isler

23. G. G. Kelley

24. J. F. Lyon

25. D. H. McNeill

26. A. T. Mense

27. M. Murakami

28. G. H. Neilson
29. M. Roberts

30. J. A. Rome

31. M. W. Rosenthal

32. D. A. Spong

33. D. Steiner

34. D. W. Swain

35. T. Uckan

36. J. B. Wilgen

37. W. R. Wing

38. S. J. Zweben

39-40. Laboratory Records Department

41. Laboratory Records, ORNL - RC

42. $Y-12$ Document Reference Section

43-44. Central Research Library

45. Fusion Energy Division Library

46. Fusion Energy Division Reports Office

47. ORNL Patent Office

\section{EXTERNAL DISTRIBUTION}

48. A. M. Budker, Nuclear Physics Institute, Siberian Academy of Sciences, Novosibirsk 90 , U.S.S.R.

49. Piero Caldirola, Laboratorio di Fisica del Plasma ed Elettronica Quantistica del C.N.R., Via Celoria, 16, 20133 Milano, Italy

50. Center for Plasma Physics and Thermonuclear Research, Physics Building 330, University of Texas, Austin, TX 78712

51. D. I. Choi, Fusion Research Center, University of Texas, Austin, TX 78712

52. T. Consoli, Centre d'Etudes Nucléaires de Grenoble, Avenue des Martyrs, 38, Grenoble, France

53. N. A. Davies, Office of Confinement Systems, Division of Magnetic Fusion Energy, Mail Code G-234, Energy Research and Development Administration, Washington, $D C 20545$

54. S. 0. Dean, Office of Confinement Systems, Division of Magnetic Fusion Energy, Mail Code G-234, Energy Research and Development Administration, Washington, $D C 20545$

55. Department of Nuclear Engineering Sciences, 202 Nuclear Science Center, University of Florida, Gainesville, FL 32611

56. Director, Technical Library, Defense Atomic Support Agency, Sandia Base, Albuquerque, NM 87115

57. A. M. Dupas, Documentation S.I.G.N., Department de la Physique du Plasma et de la Fusion Controlée, Association EURATOM-CEA sur la Fusion, Centre d'Etudes Nucléaires, BP 85 Centre du Tri, 38041 Grenoble CEDEX, France 
58. 0. C. Eldridge, Department of Physics, University of Tennessee, Knoxville, TN 37916

59. H. K. Forsen, Exxon Nuclear Co., Inc., 777 106th Ave. NE, Bellevue, WA 98004

60. T. K. Fowler, University of California, Lawrence Radiation Laboratory, P.0. Box 808, Livermore, CA 94551

61. H. P. Furth, Plasma Physics Laboratory, Princeton University, P.0. Box 451, Princeton, NJ 08540

62. G. Fussman, Max Planck Institut flir Plasmaphysik, 8046 Garching bei München, Federal Republic of Germany

63. R. W. Gould, Electrical Engineering and Physics Department, Bldg. 116-81, Californid Institute of lechnology, Pasadena, CA 91109

64. H. Grad. Courant Institute of Mathematical Scicnce, New Yơrk Universily, 251 Mercer Sẗ., New York, NY 100̄i?

65. I. Guerdsiteli, Physico-Technical Institute, Georgian Academy of Sciences, Sukhumi, U.S.S.R.

66. A. M. Hamende, International Centre for Theoretical Physics, Trieste, Italy

67. R. Hawryluk, Plasma Physics Laboratory, Princeton University, P.0. Box 451, Princeton, NJ 08540

68. T. Hsu, Office of Confinement Systems, Division of Magnetic Fusion Energy, Mail Code G-234, Energy Research and Development Administration, Washington, DC 20545

69. P. Hubert, Service de Recherches sur 1a Fusion Controlée, Centre d'Etudes Nucléaires,' Fontenay-aux-Roses (Seine), France

70. T. Kammash, 300 Auto Engineering Laboratory, University of Michigan, Ann Arbor, MI 48105

71. E. E. Kintner, Director, Division of Magnetic Fusion Energy, Mail Code G-234, Energy Research and Development Administration, Washington, DC 20545

72. H. E. Knoepfel, Laboratorio Gas Ionizzati, Associazione EURATOMCNEN, Casella Postale No. 65, Frascati (Roma), Italy

73. E. P. Lee, University of Cal ifornia, Lawrence Livermore Laboratory, P.0. Box 808, Livermore, CA 94551

74. Librarian, Controlled Thermonuclear Research Library, Lawrence Livermore Laboratory, P.0. Box 808, Livermore, CA 94551

75. Librarian, Culham Laboratory, United Kingdom Atomic Energy Authorit.y, Abingdon, Oxon 0X14 3DB, England

76. Librarian, Department of Physics and Astronomy, University of Iowa, Iowa City, IA 52240

77. Librarian, Max Planck Institut flir Plasmaphysik, 8046 Garching bei Müchen, Federal Republic of Germany

78. Librarian, Physical Sciences Laboratory, P.0. Box 6, Stoughton, WI 53589

79. Librarian, Plasma Physics Laboratory, Princeton University, P.0. Box 451, Princeton, N.] 08540

80. Librarian, Q Division Library, Los Alamos Scientific Laboratory, P.0. Box 1663, Los Alamos, NM 87544

81. Library, Centre de Recherches en Physique des Plasmas, 21 Avenue des Bains, 1007 Lausanne, Switzerland 
82. Library, FOM-Instituut voor Plasma-Fysica, Rijnhuizen, Jutphaas, The Netherlands

83. Library, General Atomic Co., P.0. Box 81608, San Diego, CA 92138

84. C. S. Liu, Department of Physics, University of Maryland, College Park, MD 20742

85. F. B. Marcus, General Atomic Co.; P.0. Box 81608, San Diego, CA 92138

86. D. G. McAlees, Research and Technology Center, Exxon Nuclear Co., Inc., 2955 George Washington Way, Richland, WA 99352

87. D. M. Meade, Plasma Physics Laboratory, Princeton University, P.0. Box 451, Princeton, NJ 08540

88. K. Molvig, Plasma Fusion Center, Massachusetts Institute of Technology, Cambridge, MA 02139

89. J. Norem, Argonne National Laboratory, 9700 S. Cass Ave., Argonne, IL 60439

90. D. Palumbo, Directorate General for Research and Training, EURATOM, 51 Rue Belliard, Brussels 5, Belgium

91. K. Papadopoulos, Naval Research Laboratory, Code 7708, Washington, DC 20375

92. Plasma Laboratory Reading Room, Massachusetts Institute of Technology, Room 20A-222, Cambridge, MA 02139

93. 0. P. Pogutse, Kurchatov Institute of Atomic Energy, 46 U1itsa Kurchatova, P.0. Box 3402, Moscow, U.S.S.R.

94. F. Prevot, Chef du Service du Confinement des Plasmas, CEA, B.P. No. 6, 92260 Fontenay-aux-Roses (Seine), France

95. M. S. Rabinovich, P. N. Lebedev Institute of Physics of the U.S.S.R. Academy of Sciences, Moscow, U.S.S.R.

96. Research Information Center, Institute of Plasma Physics, Nagoya University, Nagoya, Japan

97. J. Schmidt, Plasma Physics Laboratory, Princeton University, P.0. Box 451, Princeton, NJ 08540

98. J. D. Strachan, Plasma Physics Laboratory, Princeton University, P.0. Box 451, Princeton, NJ 08540

99. Thermonuclear Library, Kurchatov Institute of Atomic Energy, 46 Ulitsa Kurchatova, P.0. Box 3402, Moscow, U.S.S.R.

100. Research and Technical Support Division, ERDA-ORO, P.O. Box E, Oak Ridge, TN 37830

101-127. Technical Information Center, P.0. Box 62, Oak Ridge, TN 37830 